Canadian Journal of Fisheries and Aquatic Sciences

Canadian Science Publishing Journal canadien des sciences halieutiques et aquatiques

\title{
Can spawning origin information of catch or a recruitment penalty improve assessment and fishery management performance for a spatially structured stock assessment model?
}

\begin{tabular}{|r|l|}
\hline Journal: & Canadian Journal of Fisheries and Aquatic Sciences \\
\hline Manuscript ID & cjfas-2017-0523.R1 \\
\hline Danuscript Type: & Article \\
\hline Complete List of Authors: & $\begin{array}{l}\text { Li, Yang; Michigan State University, Department of fisheries and Wildlife } \\
\text { Bence, James; Michigan State University, Department of Fisheries \& } \\
\text { Wildlife } \\
\text { Brenden, Travis; Michigan State University, Department of Fisheries and } \\
\text { Wildlife }\end{array}$ \\
\hline $\begin{array}{r}\text { Is the invited manuscript for } \\
\text { consideration in a Special } \\
\text { Issue? : }\end{array}$ & N/A \\
\hline Keyword: & $\begin{array}{l}\text { intermixing, spatial structure, management strategy evaluation, statistical } \\
\text { catch-at-age, stochastic simulation }\end{array}$ \\
\hline &
\end{tabular}


1 Can spawning origin information of catch or a recruitment penalty improve

2 assessment and fishery management performance for a spatially structured stock assessment model?

$4 \quad$ Yang Li ${ }^{1}$ (email: liyang11@msu.edu)

5 Quantitative Fisheries Center, Department of Fisheries and Wildlife

6 Michigan State University, 375 Wilson Rd., UPLA Room 101

7 East Lansing, Michigan, USA, 48824-1101

$8 \quad$ James R. Bence (email: bence@msu.edu)

9 Quantitative Fisheries Center, Department of Fisheries and Wildlife,

10 Michigan State University, 375 Wilson Rd., UPLA Room 101

11 East Lansing, Michigan, USA, 48824-1101

12 Travis O. Brenden (email: brenden@msu.edu)

13 Quantitative Fisheries Center, Department of Fisheries and Wildlife

14 Michigan State University, 375 Wilson Rd., UPLA Room 101

15 East Lansing, Michigan, USA, 48824-1101

16 'Corresponding author: Yang Li (email: liyang11@msu.edu, Telephone:517-355-0003). 


\section{Abstract}

18 We used simulations based on Lake Whitefish (Coregonus clupeaformis) populations to

19 explore the benefits of using spawning origin information for parsing catch to spawning

20 populations in stock assessments for intermixed fisheries exhibiting an overlapping

21 movement strategy. We compared this origin-informed assessment model with a standard

22 assessment model that did not parse catch. We additionally evaluated the influence of

23 including annual recruitment penalties. For standard assessment models, spawning stock

24 biomass estimates could be unstable and biased (sometimes by more than $50 \%$ ),

25 depending upon population mixing and productivity, and in some cases estimated near

26 average zero recruitment in the terminal year. Incorporating information on population-

27 specific harvest age composition improved spawning stock biomass estimation (e.g., by

28 sometimes essentially removing 50\% biases, and improving accuracy). Assessments with

29 recruitment penalties produced less biased terminal recruitment estimates (sometimes a

$30100 \%$ bias was removed). Under status quo target mortality rates improvements in

31 assessments did not necessarily translate to improved fishery management performance

32 (e.g., avoiding depletion of spawning biomass), but such improvements, and overall

33 better performance, were seen at lower target mortality rates. 


\section{Introduction}

35 Accurate estimation of spawning stock biomass and recruitment is important for the 36 management of fishery stocks. Biased or imprecise estimates can influence measures of

37 population productivity and year-class strength, stock-recruitment relationships, and

38 management decisions (e.g., harvest regulations) that depend on these assessment results.

39 When fish from distinct spawning populations intermix on fishing grounds during harvest

40 periods (i.e., populations exhibit spatial structuring), estimating recruitment and

41 spawning stock biomass dynamics for each spawning population from sampling

42 programs that only target intermixed fisheries can be challenging. Statistical catch-at-age

43 or catch-at-size models are commonly used for the assessment of commercial harvested

44 fish populations for estimating biomass of spawning adults and recruitment dynamics.

45 However, one known feature of such assessment models is that recruitment in the last

46 several assessment years cannot be reliably estimated because there is little information

47 about recruitment levels for those years. In addition, such assessment models typically

48 ignore spatial structure and assume harvest is from a single population (i.e., the "unit

49 stock" assumption).

50 When assessment data are collected from intermixed fisheries but a single population

51 assumption is made in the stock assessment model, population abundance can be

52 overestimated, which can further lead to inappropriate management advice especially for

53 low productivity populations (Hutchings 1996; Fu and Fanning 2004; Ying et al. 2011;

54 Hintzen et al. 2015; Li et al. 2015). For example, it has been argued that some Atlantic

$55 \operatorname{cod}($ Gadus morhua) and Pacific salmon (Oncorhynchus spp.) populations were

56 overharvested due to intermixed fisheries that did not properly account for differences in 
57 population productivities (Hutchings 1996; Morishima and Henry 1999; Fu and Fanning

58 2004). To facilitate management of intermixed fisheries, spatially-explicit stock

59 assessment models can be used that either incorporate tagging data within the stock

60 assessment framework (Eveson et al. 2009; Vincent et al. 2017), or incorporate mixing

61 and migration rates in assessment models as fixed quantities (Guan et al. 2013; Li et al.

62 2015). Both approaches allow for spatially-explicit estimation of abundances, mortality

63 components, and other dynamic rates within an integrated stock assessment model.

64 When accounting for spatial structure in stock assessments, two alternative movement

65 strategies are commonly recognized: diffusion and overlap (Porch et al. 2001). The

66 diffusion movement strategy, also known as meta-population mixing (Ying et al. 2011),

67 assumes that the fraction of fish populations that move away from their original spawning

68 areas become part of the spawning populations near to which they move (i.e., their

69 spawning population identity changes according to their movement behavior).

70 Conversely, the overlap movement strategy assumes $100 \%$ spawning site fidelity

71 meaning that fish always move back to their original natal areas during the spawning

72 season, and thus spawning population identity is maintained throughout a fish's lifetime.

73 In this paper we focus on stock assessment models assuming an overlap movement

74 strategy. While this is clearly a simplification for any given stock, it is a reasonable

75 approximation of spatial structure for many stocks.

76 A known problem for assessment models, when applied to populations exhibiting spatial

77 structuring with moderate to high levels of intermixing, is that population-specific

78 estimates of recruitment are uncertain or not estimable, and estimates of spawning stock

79 biomass are unstable or biased, even when mixing rates are assumed known (Ying et al. 
80 2011; Molton et al. 2012; Li et al. 2015). Li et al. (2015) proposed an overlap stock

81 assessment model in which an integrated statistical catch-at-age (SCAA) assessment

82 model was fit to overlapping fish populations by incorporating actual mixing rates in the

83 model. They found that mixing among areas caused problems in estimating population-

84 specific annual recruitments, and this led to substantial uncertainty and bias in estimation

85 of recruitment and biomass. They hypothesized that this problem could be resolved if

86 additional population-specific data were provided to the assessment model, such that

87 harvest data could be allocated to source populations. Hintzen et al. (2015) evaluated the

88 influence of fishery-independent survey data on the performance of an integrated catch-

89 at-age method for intermixing fish populations, in which information on the classification

90 of the catch to their spawning origin were used to inform survey indices (i.e., the

91 proportions of survey sample to spawning populations). However, the catch data they

92 used in the assessment model were not reallocated back to the spawning populations

93 because their assessment model ignored spatial structure. Thus, mismatch between spatial

94 structures in the assessment data and in the assessment model still existed. They found

95 that spatially-explicit survey data marginally reduced bias in estimation of biomass, but

96 when there were errors in classification rates inaccuracies could actually increase.

97 The goal of our research was to evaluate the benefits of including information on catch

98 composition for the management of intermixing fish populations. Our research extended

99 the overlap SCAA assessment model proposed by Li et al. (2015) by including

100 information on population-specific harvest age composition, which could arise from

101 having genetic or some other type of discriminatory characteristic (e.g., parasite

102 community, meristic or morphometric feature) of the populations from a biological 
103 sample collected from the intermixed fisheries. Herein, we refer to the overlap

104 assessment model proposed by Li et al. (2015) as the "standard assessment model", and

105 the extended one with additional data on population source as the "origin-informed

106 assessment model". In both assessment models, annual recruitments were estimated as

107 free parameters, which is the same approach used by Li et al. (2015). We further propose

108 two alternative assessment models that are identical to these two models except that a

109 penalty on annual recruitment residuals was incorporated in each model. Several studies

110 conducted for single populations (no spatial structure) have shown that adding such

111 penalties or other constraints can improve estimates of annual recruitment, particularly

112 for terminal assessment years (Maunder and Deriso 2003; Methot et al. 2011; Korman et

113 al. 2012). We tested how assessment and management performance of the standard and

114 origin-informed assessment models were influenced by the magnitude of recruitment

115 variation, assessment data quality, uncertainty regarding mixing rates, and target

116 mortality rates.

117 The dynamics of our simulations were based on lake whitefish (Coregonus clupeaformis)

118 populations and fisheries in the upper Laurentian Great Lakes of North America,

119 although results should have general applicability to populations with similar life history

120 and movement patterns given the stochastic modeling of uncertainty and the range of

121 sensitivity analyses we report. An overlap movement strategy was assumed for the

122 simulated lake whitefish populations, because evidence suggests that lake whitefish

123 populations in the Laurentian Great Lakes region overlap during non-spawning seasons

124 but move back to where they were born during the spawning season of each year (Ebener

125 et al. 2010a; Stott et al. 2010; Li et al. 2017). Although tagging studies have suggested 
126 that considerable movement of lake whitefish in the Laurentian Great Lakes region from

127 management units containing their spawning grounds to other management units during

128 the non-spawning and harvest seasons (Ebener et al. 2010b; Li et al. 2017), they are still

129 largely managed as unit stocks. To our best knowledge, our research is the first to

130 evaluate the influence of including population-specific catch information on a spatial

131 structured stock assessment model. Compared to Hintzen et al. (2015), we propose a

132 different approach of using such information for the management of intermixing stocks

133 with a focus directed towards spatially structured stock assessments.

\section{Methods}

\section{Simulation framework}

136 Our simulation framework followed a management strategy evaluation approach (i.e., full

137 closed-loop feedback simulation framework to evaluate alternative management

138 procedures, Figure 1). These at simulations were designed to determine the long-term

139 assessment and management performance for both standard and origin-informed

140 assessment models with or without a lognormal penalty on annual recruitment residuals

141 (Table 1). The operating model consisted of four hypothetical lake whitefish populations

142 with age-structure and an overlap movement strategy (i.e., 100\% natal fidelity was

143 assumed) that intermixed across four areas of harvest. Observations from the four

144 regions of harvest were then generated for input for the stock assessment models.

145 Assessment models were fit to the observed data, and a harvest control rule was applied

146 each year based on the assessment results so that target harvest levels (i.e., total allowable

147 catch in our case) could be set. The management procedure then fed back to the operating

148 model by implementing actual harvest based on the target with implementation error in 
149 the operating model of next year. Given we were considering alternative stock

150 assessment models and the stock assessment results influenced dynamics, separate

151 simulations were conducted for each assessment approach, albeit using the same random

152 number seeds. To evaluate long-term performance of each assessment model, we ran

153 each simulation for 100 years, and summarized results for the last 25 years. All symbols

154 of index variables and accents used in the equations of this paper are identified in Table

1552.

\section{Operating model}

157 The operating model was stochastic and age-structured (i.e., ages 3 to 12 with the last age

158 class an aggregate group including age-12 and older fish), operated in annual time steps,

159 and recognized four geographic fishing grounds that were presumed to surround the four

160 spawning areas (i.e., each spawning area was associated and located within a fishing

161 region). Yearly time steps were considered because evidence suggested that the

162 movement of lake whitefish populations in the upper Great Lakes generally occurred

163 soon after spawning (i.e., between late October and early December, Li et al. 2017).

164 Thus, we assumed that fish moved away from their spawning areas on the first day of

165 each year, and all surviving fish returned to their original spawning areas to spawn at the

166 end of each year.

167 As described in detail below, many parameters of the operating model are taken from $\mathrm{Li}$

168 et al. (2015), which were based on a review of existing Lake Whitefish stock

169 assessments. A single set of life history (growth, maturity) parameters was used,

170 representative of those estimated from biological data used in those stock assessments.

171 General levels of recruitment stochasticity and productivity, and variations among 
172 populations were based on analysis of recruitment and spawning stock sizes from the

173 existing assessments. The existing assessments are unit stock assessments, and the

174 influence of this on perceived differences in recruitment productivity was taken into

175 account when specifying varying productivity levels (Li et al. 2015). In real assessments,

176 with spawning populations that differ in life history, it is likely that there would be

177 additional advantages of biological data that is spawning population specific, which we

178 have not evaluated here.

179 For each simulated population, we modeled recruitment (age-3 fish) from a Ricker stock-

180 recruitment function with a first-order autoregressive process (AR1):

$181 N_{i, y, a=3}=\alpha_{i} S S B_{i, y-3} e^{-\beta_{i} S S B_{i, y-3}} e^{\varepsilon_{R, i, y}}$.

$182 \alpha_{i}=\alpha_{i}{ }^{\prime} e^{-0.5 \sigma^{2}}$.

$183 \varepsilon_{R, i, y}=\rho \times \varepsilon_{R, i, y-1}+\tau_{R, i, y}$.

$184 \tau_{R, i, y} \sim \operatorname{Normal}\left(0,{\sigma_{R}}^{2}\right)$.

$185 \sigma^{2}=\frac{\sigma_{R}^{2}}{1-\rho^{2}}$.

186 where $N_{i, y, a=3}$ is the abundance of age- 3 fish from population $i$ at the beginning of year $y$,

$187 S S B_{i, y-3}$ is the spawning stock biomass of population $i$ in year $y-3$, and $\alpha_{i}$ and $\beta_{i}$ are

188 Ricker stock-recruitment function parameters for population $i$. The parameters $\rho$ and $\sigma_{R}$

189 defined the stochastic process for deviations of recruitment from the underlying Ricker

190 stock-recruitment function, producing temporally autocorrelated recruitment. The level of

191 process error presented in Table 3 was used for all simulated populations in the baseline

192 scenario. Process error parameters were varied in the sensitivity analysis for evaluating 
193 the influence of recruitment variation on modeling results. The stock-recruitment

194 parameter $\alpha^{\prime}$, together with $\beta$, were chosen so that the deterministic stock recruitment

195 would produce the desired average level of recruitment given stock size. For the

196 simulations, $\alpha^{\prime}$ was scaled by $e^{-0.5 \sigma^{2}}$ so that the expectation of the stochastic form of the

197 recruitment relationship would equal the deterministic value and not depend on the

198 assumed level of recruitment variation.

199 Total spawning stock biomass (SSB) for population $i$ in year $y$ was calculated as the

200 product of female percentage in the population (50\%), weight-, maturity-, and

201 abundance-at-age, and weight-specific fecundity (19733/kg). All equations and parameter

202 values used for calculating SSB are defined in Table 4, which are the same as used by Li

203 et al. (2015).

204 For each population, post-recruitment (after age-3) abundances at age (a) at the beginning

205 of each year were forward projected using an exponential mortality model with a constant

206 natural mortality $(M)$ of 0.25 , and age-, year-, and region-specific $(j)$ fishing mortality

$207(F)$ :

$208 N_{i, y+1, a+1}=N_{i, y, a} \sum_{j} \theta_{i j} \exp \left(-M-F_{j, y, a}\right)$.

209 According to equation 2, fish from a spawning population either remained in the region

210 surrounding their natal area during the non-spawning season or moved to one of the other

211 harvest areas, depending on the assumed mixing rates $\theta_{i j}$. Thus, the survival of fish in a

212 population was a weighted average of the survival rates in each of the harvest regions,

213 with weights equal to the proportions of fish from the population residing in the regions

214 during the non-spawning season. In some scenarios, mixing rates varied among the 
215 populations in the operating model, but in all cases were temporally invariant for each 216 population.

217 We used stay rate $\theta_{i i}$ (i.e., the proportion of fish from spawning population $i$ that stay in

218 the area surrounding that population's spawning area during the non-spawning season) to

219 represent movement dynamics for population $i$, and assumed that a greater stay rate

220 indicated higher-quality habitat, so that a greater proportion of fish from other population

221 moved to that area (Table 5). Thus, mixing rates $\theta_{i j}$ (i.e., the proportion of fish from

222 spawning population $i$ that move to the area surrounding population $j$ 's spawning area

223 during the non-spawning season) were calculated as (Li et al. 2015):

$224 \theta_{i j}=\left(1-\theta_{i i}\right) \frac{\theta_{j j}}{\sum_{k \neq i} \theta_{k k}}$.

225 where the summation is overall all areas $k$ except the fishing grounds surrounding the

226 spawning area of population $i$. Total allowable catch (TAC) for each harvest area was

227 determined via the management procedure described below. Actual harvest $(C)$ in each

228 year was set equal to the TAC multiplied by a lognormal implementation error term with

229 a coefficient of variation $(\mathrm{CV})$ of $10 \%$ :

$230 C_{j, y}=T A C_{j, y} \exp \left(\zeta_{j, y}-0.5 \sigma_{t a c}^{2}\right)$.

$231 \zeta_{j, y} \sim \operatorname{Normal}\left(0, \sigma_{t a c}{ }^{2}\right)$.

232 where $\sigma_{t a c}$ is the standard deviation of TAC implementation error $\zeta$. The fully selected

233 fishing mortality rate $f$ that produced the actual harvest level given age-specific

234 abundances was solved for using a Newton-Raphson algorithm and Baranov's catch 235 equation: 
$236 \quad C_{j, y}=\frac{s_{a} F_{j, y}}{M+s_{a} F_{j, y}}\left(1-e^{-M-s_{a} F_{j, y}}\right) \sum_{i} N_{i, y, a} \theta_{i j}$.

237 Age-specific $F$ s were set equal to the solved $f$ multiplied by age-specific selectivities $s_{a}$ :

$238 F_{j, y, a}=s_{a} f_{j, y}$.

239 Selectivities for age-3 and older ages were calculated from a gamma function that

240 produced a dome-shape selectivity pattern with peak selectivity for age-10:

$241 s_{a}=\frac{a^{\eta} \exp (-\tau a)}{10^{\eta} \exp (-\tau 10)}$.

242 where selectivity parameters $\tau=1.26$ year $^{-1}, \eta=13.074 \mathrm{~cm}$ (from Li et al. 2015), were

243 assumed to be the same for different populations.

244 We used the same approach as Li et al. (2015) to determine initialization abundances for

245 each simulation. Specifically, initialization abundances for the populations were set to

246 their equilibrium values based on the target mortality rate and a deterministic version of

247 our model (equilibrium for populations at different productivity levels are shown as the

248 intersections in Figure 2). As well, like Li et al. (2015), during the initial 20-year period

249 of each simulation, the harvest control rule based on the target mortality rate was applied

250 to the actual abundances at age (i.e., the assessment modeling was skipped). This was

251 necessary as prior to year 20 the required data time series for conducting assessments was

252 not available. We were not interested in the transient dynamics during this initial period,

253 and we set the starting conditions at the deterministic equilibrium solely to better ensure

254 that the final 25 years of our 100-year simulations approximated steady-state conditions.

\section{Management Procedure}


256 We attempted to emulate key aspects of the management procedures for lake whitefish in

257 the 1836 Treaty-ceded waters, including data collection, stock assessment, and

258 application of a constant total mortality harvest control rule (1836 Treaty Waters

259 Modeling Subcommittee 2017). The underlying premises were that collected data were

260 used to assess the populations (Figure 1), that the assessment results provided estimates

261 of the abundance of fish present in each region, and that target harvests were set based on

262 estimated abundances in an attempt to achieve the same target total mortality rate in each

263 harvest region. All evaluated assessment models used an integrated SCAA assessment

264 model that correctly accounted for movements (i.e., stay and mixing rates were model

265 inputs and were accurately known) among the regions, with the exception of the

266 sensitivity analyses that evaluated the consequences of uncertain mixing rates. All

267 assessment models fit the same population dynamic model to each of their observed data

268 sets to estimate the parameters used to summarize population status and determine target

269 harvest. When fitting the assessment models, only the most recent 20 years of data were

270 used. We elected to use a fixed-length time series so that the amount of information

271 available to an assessment remained stationary during the performance evaluation period

272 (the last 25 years of each 100-year simulation). While relatively short by assessment

273 standards, 20 years represents more than three times the expected period between birth

274 and production of offspring, given the assumed life history, fishery selectivity, and target

275 mortality rate in our operating model, based on Lake Whitefish. Simulations using a 40-

276 year assessment period for a subset of scenarios produced nearly identical results to those

277 with the 20-year assessment period. Age range of the assessment models was the same as

278 that of the operating model. By minimizing the negative log-likelihood (see objective 
279 function subsection below), the assessment models were considered to have converged on

280 a solution when the maximum gradient of the parameters was less than 0.001 , and the

281 Hessian matrix was positive definite. Convergence rate is defined as the fraction of

282 simulations that met both of the above criterions.

283 For the standard assessment models with or without a recruitment penalty (i.e., S and S

$284 \mathrm{~W} /$ Rec in Table 1), observed harvest, effort, and aggregated (across populations) harvest

285 age composition data were collected annually for each region. For the origin-informed

286 assessment models (i.e., $\mathrm{O}$ and $\mathrm{O} \mathrm{W} / \mathrm{Rec}$ in Table 1), observed harvest, effort, and

287 population-specific harvest age composition data were collected annually for each region.

288 Observed harvest differed from actual harvest as a result of observation error, which was

289 modeled with a $\operatorname{lognormal}$ error term $v$ :

$290 \tilde{C}_{j, y}=C_{j, y} \exp \left(v_{y}-0.5 \sigma_{c}^{2}\right)$.

$291 v_{y} \sim \operatorname{Normal}\left(0, \sigma_{c}{ }^{2}\right)$.

292 The observed fishing effort was a function of fishing mortality $f$, catchability $q$, and a

293 lognormal observation error $\mu$ and we assumed $\sigma_{F}^{2}=4 \sigma_{c}{ }^{2}$.

$294 \quad E_{j, y}=\frac{f_{j, y}}{q} \exp \left(\mu_{j, y}-0.5 \sigma_{F}^{2}\right)$.

$295 \mu_{j, y} \sim \operatorname{Normal}\left(0, \sigma_{F}^{2}\right)$.

296 In the baseline scenario, baseline level of CVs for the error terms of observed harvest and

297 effort were used (Table 3) while different levels of CVs were explored in the sensitivity

298 analyses for data quality. 
299 For the standard assessment models, aggregated observed age compositions for area-

300 specific harvests were generated from multinomial distributions with probabilities equal

301 to the actual age composition. For the origin-informed assessment models, observed

302 population-specific age compositions for area-specific harvests were generated from

303 multinomial distributions with probabilities equal to the actual population-specific age

304 compositions in each region. The effective sample size $\left(N_{e f f}\right)$ for the multinomial

305 distribution used to generate aggregated and population-specific age compositions was

306 assumed at its baseline level (Table 3), except for the sensitivity analyses for data quality.

307 Recruitment $\left(\widehat{N}_{i, y, a=3}\right)$ of each assessment year, abundances at age (except age at

308 recruitment) in the first assessment year $\left(\widehat{N}_{i, y=1, a>3}\right)$, gamma function selectivity

309 parameters $(\hat{\tau}, \hat{\eta})$, catchability $(\hat{q})$, the annual deviation from general level of fishing

310 mortality $\left(\widehat{\varepsilon F}_{j, y}\right.$, Fournier and Archibald 1982), and the standard deviation from observed

311 harvest $\left(\hat{\sigma}_{c}\right)$ were estimated during assessment model fitting. Recruitments in the standard

312 and origin-informed assessment models without recruitment penalty were estimated as

313 free parameters. For the assessment models that included a recruitment penalty,

314 recruitment for each population was reparameterized as the product of average

315 recruitment $\left(\widehat{R \mu}_{l}\right)$ multiplied by an annual residual $\left(\varepsilon^{\prime} y\right)$ that was exponentiated and bias

316 corrected, so that the annual recruitment was assumed to come from a lognormal

317 distribution:

$318 N_{i, y, a=3}^{\prime}=\widehat{R \mu_{l}} e^{\varepsilon y^{-0.5 \sigma_{R}}}$.

$319 \varepsilon^{\prime}{ }_{y} \sim \operatorname{Normal}\left(0, \sigma_{R}^{\prime}\right)$. 
320 Post-recruit abundances at age in the first assessment year were estimated as free

321 parameters. The fishing mortality in the assessment models was modeled in the same way

322 as for the operating model, which was a product of selectivity at age and fully selected

323 fishing mortality (same as in Equations 6 and 7, but here $\hat{\tau}$ and $\hat{\eta}$ were estimated

324 parameters). The fully selected fishing mortality $\left(f_{j, y}^{\prime}\right)$ was modeled as a product of

325 assessed catchability $(\hat{q})$, observed effort $\left(\tilde{E}_{j, y}\right)$, and assessed annual deviation from

326 general level of fishing mortality $\left(\widehat{\varepsilon F}_{j, y}\right)$.

327 The natural mortality rates assumed in all assessment models were the same as those used

328 for the operating model. The parameters of all assessment models were estimated in AD

329 Model Builder (Fournier et al. 2012).

330 The population dynamics in all stock assessment models (i.e., S, S W/Rec, O, and O

331 W/Rec) followed:

$332 N_{i, y+1, a+1}^{\prime}=N_{i, y, a}^{\prime} \sum_{j} \theta_{i j} \exp \left(-M-F_{j, y, a}^{\prime}\right)$.

$333 C_{j, y, i, a}^{\prime}=\frac{F^{\prime}{ }_{j, y, a}}{M+F^{\prime}{ }_{j, y, a}}\left(1-e^{-M-F^{\prime} j, y, a}\right) N_{i, y, a}^{\prime} \theta_{i j}$

$334 C_{j, y, a}^{\prime}=\sum_{i} C_{j, y, i, a}^{\prime}$

335 For each harvest area, aggregated harvest age composition for the standard assessment

336 models (Equation 14, Table 1), and population-specific harvest age composition for the

337 origin-informed assessment models (Equation 15, Table 1) were:

$338 p_{j, y, a}^{\prime}=C_{j, y, a}^{\prime} / \sum_{a} C_{j, y, a}^{\prime}$.

$$
p_{j, y, i, a}^{\prime}=C_{j, y, i, a}^{\prime} / \sum_{i, a} C_{j, y, i, a}^{\prime}
$$


340 Predicted SSB was calculated from estimated abundance at age $N_{i, y, a}^{\prime}$ by using equation

341 1, and assuming weight, maturity at age and weight-specific fecundity were known

342 (Table 4).

\section{Objective function}

344 The objective function for each assessment model was the summation of at least three

345 negative log-likelihood and log-prior/penalty components (Table 1). All four assessment

346 models assumed the same lognormal distributions for the log-likelihood component of

347 total fishery annual harvest by harvest area and for the log-prior components associated

348 with the fishing mortality-effort relationship for each harvest area.

349 The total negative log-likelihood component for the log of area-specific annual fishery

350 harvest was based on a normal distribution

$351 \ell_{c}=\sum_{j}\left(n \log _{e}\left(\hat{\sigma}_{c}\right)+\left(\frac{1}{2{\hat{\sigma}_{c}}^{2}}\right) \sum_{y}\left(\log _{e}\left(\frac{\tilde{c}_{j, y}}{\hat{\bar{j}}_{j, y}}\right)\right)^{2}\right)$,

352 where $n$ was the number of assessment years (i.e., 20 years). A normal distribution was

353 also assumed for the log-prior penalty associated with the log annual deviation from the

354 general level of fishing mortality

$355 \ell_{\varepsilon F}=\sum_{j}\left(n \log _{e}\left(\sigma_{F}{ }^{\prime}\right)+\left(\frac{1}{2{\sigma_{F}}^{\prime 2}}\right) \sum_{y}\left(\log _{e}\left(\widehat{\varepsilon F}_{j, y}\right)\right)^{2}\right)$,

356 where ${\sigma_{F}}^{\prime 2}$ was assumed to be four times greater than $\hat{\sigma}_{c}{ }^{2}$, which matched what was

357 assumed in the operating model. This penalty was equivalent to predicting effort as

358 proportional to estimated fishing mortality and treating deviations between the log of

359 observed and predicted fishing effort as normally distributed (Fournier and Archibald 360 1982). 
361 The third likelihood component was associated with harvest age composition and was

362 based on a multinomial distribution, but there were differences in this likelihood

363 component for standard and origin-informed assessment models. For the standard

364 assessment model (assessment models S and S W/Rec, Equation 18), the negative log

365 likelihood component was for the aggregate harvest age composition for the harvest

366 regions

$367 \ell_{a}=-\sum_{j} \sum_{y} N_{e f f} \sum_{a}\left(\tilde{p}_{j, y, a} \log _{e} p_{j, y, a}^{\prime}\right)$.

368 where $\tilde{p}_{j, y, a}$ and $p_{j, y, a}^{\prime}$ are the observed and estimated proportions of harvest in area $j$ by

369 age $a$ in year $y$ and $N_{e f f}$ is the assumed effective sample size. For the origin-informed

370 assessment models (assessment models $\mathrm{O}$ and $\mathrm{O}$ W/Rec, Equation 19), the negative log

371 likelihood component was for the population-specific harvest age composition for the

372 harvest regions

$373 \ell_{p a}=-\sum_{j} \sum_{y} N_{e f f} \sum_{i, a}\left(\tilde{p}_{j, y, i, a} \log _{e} p_{j, y, i, a}^{\prime}\right)$.

374 where $\tilde{p}_{j, y, i, a}$ and $p_{j, y, i, a}$ are the observed and estimated proportions of harvest in area $j$

375 by age $a$ from population $i$ in year $y$, respectively. For baseline scenarios, $N_{e f f}$ was set

376 equal to 50 for both standard and origin-informed assessment models, but was varied in

377 sensitivity analyses to evaluate the influence of data quality.

378 For standard and origin-informed assessment models that included a penalty on annual

379 recruitment residuals (i.e., $\mathrm{S} \mathrm{W} / \mathrm{Rec}$ and $\mathrm{O} \mathrm{W} / \mathrm{Rec}$ in Table 1), the objective function

380 included a $\log$-penalty component that constrained the annual recruitment residuals $\varepsilon^{\prime}{ }_{y}$ of

381 equation 10 based on a normal distribution with standard deviation $\sigma_{R}^{\prime}$ equal to 2.0 . In

382 other words, the log-penalty on annual recruitment residuals was modeled as 
$383 \ell_{R}=\sum_{j}\left(\sum_{y} \log _{e}\left(\sigma_{R}^{\prime}\right)+\frac{\varepsilon^{\prime} y^{2}}{2 \sigma_{R^{2}}^{2}}\right)$.

\section{Application of the harvest control rule}

385 To mimic the timing of implementing assessments and setting harvest targets of lake

386 whitefish fisheries in 1836 Treaty-ceded waters, we included a one-year lag between data

387 collection and incorporation in the four stock assessment models. More specifically, an

388 annual assessment was conducted each year of a simulation based on data collected

389 through the previous year, to set the harvest targets for the following year. In the lag year,

390 abundances were projected based on an exponential population model where total

391 mortality rates were assumed to be the mean of the last three years' value, and

392 recruitments were assumed to be the mean of the most recent 10 years. During the year

393 of setting harvest targets (after the lag year), we used the same approach as in the lag year

394 to project abundance at the beginning of that year. We then used Baranov's catch

395 equation (same as in equation 12 and 13) to calculate harvest target, while the fishing

396 mortality rates were adjusted to the target fishing mortality rates, which can be calculated

397 based on target mortality rates, estimated selectivity-at-age, and natural mortality rate.

\section{Simulation Scenarios}

399 We evaluated five productivity and movement scenarios (Table 5), and six sensitivity

400 analysis scenarios (Table 3 and 6). We also evaluated all cross-combinations of

401 productivity/movement scenarios and sensitivity analysis, and full results are available in

402 the supplementary material. For each evaluated scenario, 200 simulations were

403 conducted. In the baseline scenario (Table 5), we assumed the four simulated populations

404 had equal stay rates and productivity levels to establish a baseline for comparison of 
405 assessment and management performance results. Then we explored alternative operating

406 model settings with different productivity and movement assumptions, to evaluate the

407 consequences of different combinations of productivity and movement dynamics of lake

408 whitefish populations on stock assessments. We also evaluated outcome sensitivity to

409 different quality of assessment data, uncertain mixing rates assumptions, and recruitment

410 variability.

411 Baseline scenario and alternative productivity and movement scenarios

412 We explored five scenarios of population-specific movement dynamics and productivity

413 (scenario 1 is the baseline scenario) (Table 5). Overall, there were three different levels of

414 productivity (i.e., low, baseline, and high), and three different stay rates during non-

415 spawning season (low, medium, high). Each productivity level corresponded to a specific

416 steepness parameter, and different productivity levels shared the same unfished

417 equilibrium spawning stock size (Table 3). However, higher productivity levels would

418 lead to greater fished equilibrium stock size and recruit levels (Figure 2). Target

419 mortality rate (Target_A; annual death rate=1.0-annual survival rate) was assumed to be

$420 \quad 0.65$ as a baseline level, which is the current rate used in 1836 Treaty-ceded management

421 of lake whitefish, although as part of sensitivity scenarios explored the effects of a lower

422 target mortality rate.

423 In the baseline scenario (scenario 1), the four populations had identical "baseline"

424 productivity and stay rates set to "medium" levels. Scenario 2 explored a case in which

425 the four populations still had equal medium levels of movement, but two of the

426 populations had low productivity while the other populations had high productivity. In

427 scenarios 3 to 5, the four populations had different stay rates and either had equal 
428 productivity levels (scenario 3 ) or unequal productivity levels (scenario 4: positive

429 correlation between productivity level and stay rate; scenario 5: negative correlation

430 between productivity level and stay rate).

431 Sensitivity Analyses

432 A total of six sensitivity scenarios (Table 6) were conducted to determine whether

433 baseline results remained consistent after modifying specific conditions of the examined

434 scenario (e.g., poor data quality). The purpose of the sensitivity analyses was to

435 determine the general applicability of model results.

436 Data Quality - The first two sensitivity scenarios considered different levels of data

437 quality available for assessment models: low and high (relative to the baseline level), by

438 varying effective sample size $\left(N_{\text {eff }}\right)$ and the CVs for harvest and effort (Tables 3 and 6).

439 The low and high levels of data quality were chosen to reflect the extreme data quality

440 cases evaluated by Li et al. (2016) based on ranges seen in retrospective errors for actual

441 lake whitefish stock assessments in the 1836 Treaty-ceded waters.

442 Uncertain Mixing Rates - In the baseline scenario, the mixing rates were consistent

443 across populations and simulation years in the operating model, and assumed as correctly

444 known parameters in the stock assessment model. In the third sensitivity scenario, we

445 assumed that annual stay rates in the assessment models were still treated as known

446 parameters, but did not match the true $\theta_{i i}$ in the operating model. The annually varying

447 stay rates $\theta_{i i, y}$ used in the assessment model were parameterized by a 'logistic' function

448 of re-parameterized rates $\left(\omega_{y}\right)$

$449 \theta^{\prime}{ }_{i i, y}=\exp \left(\omega_{y}^{\prime}\right) /\left(\exp \left(\omega_{y}^{\prime}\right)+1\right)$. 
450 The annual values for $\omega^{\prime} y$ were generated from a normal distribution (Table 3). Different

451 sets of mean and variance values were assumed to ensure the annually varying stay rates

452 used in the assessments were within $10 \%$ of the true $\theta_{i i}$.

453 Recruitment Variation-For the next two sensitivity scenarios, we explored two

454 recruitment variability levels (Table 3 and Table 6). In the high recruitment variability

455 scenario, we kept the autocorrelation coefficient at 0.45 as in the baseline scenario but

456 increased the stationary standard deviation in the recruitment process error to 1.5. For the

457 second level, we removed the autocorrelation component of recruitment variation so that

458 the recruitment variation was simply white noise, and kept the same stationary variance

459 as for the baseline scenario.

460 Target mortality - For the last sensitivity scenario, a lower target mortality rate

461 (Target_A) of 0.55 was implemented in the management procedure because this rate has

462 been identified as sustainable for a wide range of lake whitefish populations with

463 different productivities ( $\mathrm{Li}$ et al. 2015).

\section{Performance Statistics}

465 Performance statistics for evaluating the different assessment models were average SSB,

466 the proportion of years SSB was less than $20 \%$ of the unfished SSB level ( $\mathrm{P}\left(\mathrm{SSB}<\mathrm{B}_{20} \%\right)$ ),

467 average annual total yield and inter annual variation (IAV) in yield by area, relative error

468 (RE) in the terminal assessment year SSB, and RE of estimating recruitment for all

469 assessed years, over the last 25 years of the simulations. Relative error was calculated as

$470 R E=(\bar{x}-x) / x$, where $\bar{x}$ is the predicted value based on the assessment results and $x$ is

471 the true value generated from the operating model. We additionally estimated the

472 autocorrelation in RE in the terminal assessment year SSB over the last 25 years for each 
473 simulation. This was intended to assess autocorrelation in assessment errors under

474 stationary conditions. The autocorrelation was estimated by fitting an AR1 model to the

475 time series of REs in terminal SSB resulting from each simulation by ordinary least

476 squares. We used the ar.ols function from stats package in R 3.2.2 for the autocorrelation

477 coefficient (ARC) calculation (R Core Team 2016). A large positive ARC would imply

478 that the assessment errors tended to be similar for multiple years in a row. The

479 distributions of the performance statistics calculated over all 200 simulations for an

480 evaluated scenario, were summarized by the median and inter-quartile range. We choose

481 to run 200 simulations because preliminary results of the baseline scenario suggested that

482 results from 200 simulations were nearly identical from those based on 1000 simulations.

\section{Results}

484 In general, all four assessment models converged on solutions. Convergence rate of the 485 assessments was $>93 \%$ across all scenarios for the origin-informed model $(\mathrm{O})$, the origin-

486 informed model with recruitment penalty $(\mathrm{O}$ W/Rec), and the standard model with

487 recruitment penalty $(\mathrm{S} \mathrm{W} / \mathrm{Rec})$. Although the convergence rate of the standard assessment

488 model (S) was 95\% for the baseline scenario, it was less than $90 \%$ for other evaluated

489 scenarios. Including a recruitment penalty increased the convergence rate for both

490 standard and origin-informed models by $8.0 \%$ and $1.7 \%$ on average across all scenarios,

491 with the largest improvement in convergence by $20.8 \%$ for the standard assessment

492 approach under scenario 5 with low data quality (Tables 5 and 6).

\section{Baseline scenario}

494 Under the baseline scenario, where the simulated populations had the same stay rates and 495 productivity levels, the expected assessment and management performance was the same 
496 across all populations, and indeed the realized performance results were nearly identical

497 (see full results in Supplementary material). Consequently, we summarize the results for

498 only one of the four populations (i.e., Population 1 in Table 5). Compared to the standard

499 assessment models (i.e., S and S W/Rec), adding population-specific harvest age

500 composition in the origin-informed assessment models (i.e., $\mathrm{O}$ and $\mathrm{O} \mathrm{W} / \mathrm{Rec}$ ) in general

501 resulted in less bias and more weakly autocorrelated estimates of SSB in the terminal

502 assessment year with smaller inter-quartile ranges (Figures 3a and 3f), and less

503 uncertainty in estimates of recruitment (based on smaller inter-quartile ranges of RE)

504 over all assessment years except for the final two years (Figure 3b). However, the origin-

505 informed assessment model performance did not translate into benefits in the

506 management performance statistics, such as average true SSB and yield, with only

507 slightly improvement in the IAV of yield (3c, 3d and 3e, and supplementary materials).

508 When a recruitment penalty was added to both the standard and origin-informed

509 assessment models (comparing $\mathrm{S}$ W/Rec and $\mathrm{O}$ W/Rec with $\mathrm{S}$ and $\mathrm{O}$ ), this resulted in less

510 IAV of yield (median IAV of yield decreased by 0.05 and 0.04 for standard and origin-

511 informed models, Figure 3e), and lower bias in estimates of recruitment for the last two

512 assessment years (Figure 3b), but slightly higher risk of SSB being lower than 20\% of its

513 unfished level (median $\mathrm{P}\left(\mathrm{SSB}<\mathrm{B}_{20 \%}\right.$ ) increased by $3.8 \%$ and $7.7 \%$, Figure $3 \mathrm{c}$ ).

514 Both the standard and origin-informed assessment models without recruitment penalties

515 had considerable difficulty in estimating recruitment levels in the terminal assessment

516 year. In most simulations, the recruitment RE in the terminal assessment year was $-100 \%$,

517 meaning that recruitment was being estimated at essentially 0 fish (Figure $3 \mathrm{~b}$ and 4 ).

518 However, when a recruitment penalty was included in the assessments (comparing S 
$519 \mathrm{~W} / \mathrm{Rec}$ with $\mathrm{O} \mathrm{W} / \mathrm{Rec}$ ), the origin-informed assessment model (i.e., $\mathrm{O} \mathrm{W} / \mathrm{Rec}$ ) produced

520 less biased estimates for the terminal assessment year recruitment (Figure 3b and Figure

$5214)$.

522 Alternative productivity and movement scenarios

523 For the alternative productivity and movement scenarios, we present results only for

524 populations 1 and 3 because for these scenarios populations 1 and 2 and populations 3

525 and 4 had nearly identical results due to their same productivity and stay rates. When low

526 and high productivity populations intermixed (Scenario 2, 4, and 5 in Figure 5), low

527 productivity populations generally had high risk of being overfished (i.e., the interquartile

528 ranges of average true SSB were below $20 \%$ of the unfished level) across all scenarios.

529 Regardless of whether a penalty for annual recruitment residuals was included, the

530 origin-informed assessment models (i.e., $\mathrm{O}$ and $\mathrm{O} \mathrm{W} / \mathrm{Rec}$ ) substantially outperformed the

531 standard assessment models ( $\mathrm{S}$ and S W/Rec) in terms of estimation of SSB of the

532 terminal assessment year for low productivity populations, but using population-specific

533 harvest age composition data had only a slight influence on estimation of SSB for high

534 productivity populations. More specifically, for the low productivity populations, the RE

535 of estimated terminal assessment year SSB in year 100 was less biased, and the

536 autocorrelation for these estimates over the last 25 years was lower for assessment

537 models $\mathrm{O}$ and $\mathrm{O} \mathrm{W} / \mathrm{Rec}$ than for $\mathrm{S}$ and $\mathrm{S} \mathrm{W} / \mathrm{Rec}$. Such differences in assessment

538 performance were greater for scenarios where there was a negative correlation between

539 stay rates and productivity. For the scenario where populations had the same productivity

540 but different stay rates (Scenario 3), assessment performance results were similar to those

541 of the baseline scenario. 
542 With respect to the estimation of terminal assessment year recruitment and for

543 management performance statistics, results for all alternative productivity and movement

544 scenarios were similar to those found in the baseline scenario. Neither the standard or

545 origin-informed assessment models without recruitment penalties could produce reliable

546 estimates of recruitment in the terminal assessment year. When low productivity

547 populations intermixed with high productivity populations (Scenario 2, 4, and 5 in Figure

548 5), standard and origin-informed assessment models with recruitment penalties resulted

549 in unbiased recruitment estimates in the terminal assessment year for high productivity

550 population, but positive bias in recruitment estimates in the terminal assessment year for

551 low productivity populations.

552 Sensitivity Analyses

553 The assessment and management performances for all the assessment models were

554 generally insensitive to changes in the magnitude of actual recruitment variation, target

555 mortality, data quality, and to uncertain mixing rates assumptions (Figure 6), with

556 patterns in performance statistics similar to those of the baseline scenario. There were

557 only three exceptions. First, with a lower total mortality target (55\%), the origin-informed

558 assessment models both with and without recruitment penalties had better management

559 and assessment performance than the standard assessment models, as evidenced by lower

$560 \mathrm{P}\left(\mathrm{SSB}<\mathrm{B}_{20} \%\right)$ (median at 0.08 for $\mathrm{O}$ and at 0.12 for $\left.\mathrm{S}\right)$, similar or even higher yield

561 (median at 204.8 for $\mathrm{O}$ and at 204.2 for S), lower IAV of yield (median at 0.32 for $\mathrm{O}$ and

562 at 0.35 for S), and less biased with smaller inter-quartile range (inter-quartile range [-

$5630.13,0.10]$ for $\mathrm{O}$ and $[-0.18,0.15]$ for S), and less autocorrelated estimates of SSB (median

564 at 0.37 for $\mathrm{O}$ and at 0.44 for $\mathrm{S}$ ) in the terminal assessment year. Second, when 
565 recruitment variation was high, $\mathrm{P}\left(\mathrm{SSB}<\mathrm{B}_{20} \%\right)$ was higher, and average yields were lower

566 for all four assessment models. In addition, for this high recruitment scenario both

567 assessment models with recruitment penalties tended to overestimate recruitment

568 (RecV_H in Figure 6). Finally, when assessment data quality was low (RecV_L in

569 Figure 6), all four assessment models tended to underestimate SSB, have greater IAV of

570 yield, and greater inter-quartile range for the RE of estimating terminal year SSB.

\section{Discussion}

572 Attempting to account for movement in fish stock assessment models has become

573 increasingly common for the management of intermixed fisheries (Cope and Punt 2011;

574 Ying et al. 2011; Molton et al. 2012; Li et al. 2015; Vincent et al. 2017). In this study, we

575 evaluated four spatially-structured SCAA models (standard assessment, standard

576 assessment with recruitment penalty, origin-informed assessment, origin-informed

577 assessment with recruitment penalty) for assessing lake whitefish populations that were

578 assumed to exhibit an overlap movement strategy. We aimed to evaluate if considering

579 additional assessment data about classification of catch to spawning origin, and adding a

580 penalty for annual recruitment residuals, could improve the assessment and management

581 performance of the overlap SCAA model proposed by Li et al. (2015). We found that

582 data allowing parsing of catch from a management area to the specific spawning

583 population the fish came from could result in less biased and less auto-correlated

584 estimates of spawning stock biomass (SSB) in terminal assessment years, and less

585 uncertainty in estimates of recruitment early in the time period assessed; while including

586 a lognormal penalty on annual recruitment residuals in assessment models substantially 
587 improved the estimation of recruitment in the terminal assessment years. With the

588 penalty, data on population source also led to improved terminal recruitment estimates.

589 When we used data on the classification of catch to spawning origin in our proposed

590 overlap assessment models, we assumed a multinomial distribution of population-age

591 composition for each year of harvest from an area. This is an extension of what we

592 assumed in our standard SCAA model in which a multinomial distribution was assumed,

593 as is often done, for age composition of harvest. Use of these additional data did provide

594 better estimation of the spawning stock biomass (SSB) in the terminal assessment year.

595 Hintzen et al. (2015) reached a similar conclusion but with a small level of improvement

596 when they used such data to inform survey indices for an integrated stock assessment

597 model. This may be due to the mismatch between the spatial structures in their

598 assessment data of catch and in the assessment model. Although spawning origin

599 information allowed the assessment model to incorporate correct (or with uncertainty)

600 survey indices, because their assessment model ignored spatial structure in the observed

601 catch data such a mismatch can still lead to biased estimation of biomass and recruitment.

602 Our results suggested that such improvements in assessment performance did not

603 necessarily translate into improved management performance, except when we used a

604 lower than status-quo mortality target. Under the status-quo mortality target, although the

605 origin-informed assessment models provided better estimation of SSB than the standard

606 overlap models, the calculated total allowable catch (TAC) based on the estimated SSB

607 was still not sustainable. Coincidentally, because the standard assessment models tended

608 to underestimate SSB, it resulted in a more "appropriate/conservative" TAC. This

609 argument is evidenced by our sensitivity analysis with lower target mortality rate 
610 (Target_A $=55 \%$ ) in which origin-informed assessment models had better management

611 and assessment performance than standard assessment models.

612 Past studies have found that when populations with different productivity levels intermix

613 during harvest season, populations with lower productivity are generally more vulnerable

614 to overharvest (Ricker 1958; Paulik et al. 1967; Hintzen et al. 2015; Li et al. 2015). The

615 results from this study are consistent with those studies. We found that there was a high

616 risk of being overfished for low productivity populations, especially when low

617 productivity populations with high stay rates intermixed with high productivity

618 populations with low stay rates. In such a case, for low productivity populations, standard

619 assessment models tended to overestimate SSB, while the origin-informed assessment

620 models provided nearly median unbiased estimation of SSB. We suspect that the standard

621 assessment model is challenged to identify the correct age composition for low

622 productivity populations from the aggregate sample collected from each harvest area,

623 because they consist of mixtures of age compositions from populations with different

624 productivity, with contributions depending on population productivities and movement

625 rates. Conversely, information on population-specific age compositions for area-specific

626 harvests provides sufficient information to prevent inaccuracies in SSB estimates.

627 Our sensitivity analysis suggested that the improvement by including population-specific

628 age compositions for area-specific harvests was limited to scenarios without high

629 assessment data quality. In other words, when data quality is high, standard assessment

630 models can provide sufficiently accurate estimates of population-specific SSB when

631 supplied with accurate mixing rates. Thus, an origin-informed assessment model may not

632 be necessary in conditions of high data quality and accurate information on mixing. We 
633 must emphasize that our consideration of data quality was focused on precision rather

634 than potential biases in data. We also did not consider model misspecification except for

635 the unmatched mixing rates assumed in the operating and assessment models in the

636 sensitivity analyses, and our stochastic assumptions regarding recruitment for the models

637 with recruitment penalties. A formal evaluation of how model misspecification affects the

638 performance of spatially structured stock assessment model was outside the scope of our

639 research but we would encourage investigations on this topic. We anticipate

640 consequences of model misspecification to be case specific. Some cases of model

641 misspecification may change the scale of biomass assessment, and this would not change

642 the relative performance of the four assessment models we evaluated because target $F$ in

643 all assessment models would be adjusted to count for bias in similar manners. In other

644 cases, however, model misspecification may lead to too high estimation errors. In such

645 there may not be a strong justification for collecting population-specific data because the

646 advantages of origin-informed assessment models over the standard models may not be

647 clear.

648 The other major finding from this research was that including a lognormal penalty on

649 annual recruitment residuals in both standard and origin-informed assessment models

650 markedly improved the estimation of recruitment at the end of the assessment period.

651 This is consistent with what has been found in evaluations of stock assessments without

652 spatial structure (Maunder and Deriso 2003; Methot et al. 2011; Korman et al. 2012).

653 Although the inclusion of a recruitment penalty did not prevent recruitment from being

654 overestimated when recruitment variation in the operating model was high, its

655 performance was still better than when a recruitment penalty was not included. This 
656 overestimation may stem, in part, from the large standard deviation for the distribution

657 governing the annual recruitment deviations in the assessment models with recruitment

658 deviations. We also found that IAV of yield was lower when a recruitment penalty was

659 incorporated. This may result from the more stable/reasonable estimation of recruitment

660 at the end of the assessment year period. Such stabilization of recruitment estimates can

661 lead to a more stable prediction of future abundance, and that is what the TAC calculation

662 is based on. Also, because we included a 1-year lag between assessment data collection

663 and assessment model implementation to mimic the real management procedure for lake

664 whitefish in Laurentian Great Lakes region, the impact of recruitment estimation near the

665 end of the time series is magnified, given we needed to project an additional year over

666 what is assumed in some studies.

667 In summary, we found that for a spatially structured SCAA model that incorporated

668 information on population-specific age composition of harvest resulted in less biased and

669 less correlated estimates of spawning stock biomass (SSB) in terminal assessment years,

670 and less uncertainty in estimating recruitment in early assessment years. Including a

671 lognormal penalty on annual recruitment residuals in the spatial structured SCAA model

672 substantially improved the estimation of recruitment in the terminal assessment years,

673 which we suggest as "best practice" for spatially-structured assessment models. Despite

674 the improved assessment performance, preventing overharvest of low productivity

675 populations when using such assessments will still require an appropriate harvest policy,

676 such as lower target mortality rates or precautionary reference points. Different

677 approaches for parsing catch to contributing populations are likely to have different levels

678 of classification accuracy. For example, genetic classification methods may be more 
679 accurate than otolith microchemistry methods if there are not strong environmental

680 differences among spawning locations. Further research into how assessment model

681 performance is affected by classification accuracy would be beneficial. We also

682 recommend additional investigation of factors such as the inclusion of more complex

683 spatial structure (e.g., seasonal movement), alternative harvest policies, model

684 misspecification, and alternative spatial structured stock assessment models (e.g.,

685 spatially structured virtual population analysis, tag integrated assessment model) to

686 evaluate the benefits of parsing catch to spawning populations when it comes to the

687 management of spatially-structured populations.

688 Acknowledgements

689 Funding for this project was provided by the Great Lakes Fishery Commission (Project

690 2013_BRE_44025) and Great Lakes Fishery Trust (Project 2012.1250). Additional

691 funding support was provided by supporting partners of the Quantitative Fisheries Center

692 and Michigan Department of Natural Resources through the Partnership for Ecosystem

693 Research and Management program. We acknowledge the support of the Michigan State

694 University High Performance Computing Center and the Institute for Cyber-Enabled

695 Research. We wish to thank the Modeling Subcommittee of the Technical Fisheries

696 Committee for 1836 Treaty-ceded waters for providing input on our research. This is

697 publication 201X-XX of the Michigan State University Quantitative Fisheries Center.

698 Reference

6991836 Treaty Waters Modeling Subcommittee, Technical Fisheries Committee. 2017.

700 Technical fisheries committee administrative report 2017: status of lake trout and

701 lake whitefish populations in the 1836 treaty-ceded waters of Lakes Superior, Huron

702

703 and Michigan, with recommended yield and effort levels for 2017. doi:10.13140/RG.2.2.19581.15844. 
704

705

706

707

708

709

710

711

712

713

714

715

716

717

718

719

720

721

722

723

724

725

726

727

728

729

730

731

732

733

734

735

736

737

738

739

740

741

742

743

744

Cope, J.M., and Punt, A.E. 2011. Reconciling stock assessment and management scales under conditions of spatially varying catch histories. Fish. Res. 107(1-3): 22-38. doi:10.1016/j.fishres.2010.10.002.

Ebener, M.P., Brenden, T.O., and Jones, M.L. 2010a. Estimates of fishing and natural mortality rates for four lake whitefish stocks in northern Lakes Huron and Michigan. J. Great Lakes Res. 36: 110-120. doi:10.1016/j.jglr.2009.06.003.

Ebener, M.P., Brenden, T.O., Wright, G.M., Jones, M.L., and Faisal, M. 2010b. Spatial and temporal distributions of lake whitefish spawning stocks in Northern lakes Michigan and Huron, 2003-2008. J. Great Lakes Res. 36: 38-51. doi:10.1016/j.jglr.2010.02.002.

Eveson, J.P., Laslett, G.M., and Polacheck, T. 2009. A spatial model for estimating mortality rates, abundance and movement probabilities from fishery tag-recovery data. In Modeling Demographic Processes In Marked Populations. doi:10.1007/9780-387-78151-8.

Fournier, D.A., Skaug, H.J., Ancheta, J., Ianelli, J., Magnusson, A., Maunder, M.N., Nielsen, A., and Sibert, J. 2012. AD Model Builder: using automatic differentiation for statistical inference of highly parameterized complex nonlinear models. Optim. Methods Softw. 27(2): 233-249. doi:10.1080/10556788.2011.597854.

Fournier, D., and Archibald, C.P. 1982. A general theory for analyzing catch at age data. Can. J. Fish. Aquat. Sci. 39(8): 1195-1207. doi:10.1139/f82-157.

Fu, C., and Fanning, L.P. 2004. Spatial considerations in the management of Atlantic cod off Nova Scotia, Canada. North Am. J. Fish. Manag. 24(3): 775-784. doi:10.1577/M03-134.1.

Guan, W., Cao, J., Chen, Y., Cieri, M., and Quinn, T. 2013. Impacts of population and fishery spatial structures on fishery stock assessment. Can. J. Fish. Aquat. Sci. 70(8): 1178-1189. doi:10.1139/cjfas-2012-0364.

Hintzen, N.T., Roel, B., Benden, D., Clarke, M., Egan, A., Nash, R.D.M., Rohlf, N., and Hatfield, E.M.C. 2015. Managing a complex population structure: exploring the importance of information from fisheries-independent sources. ICES J. Mar. Sci. 72(2): 528-542. doi:10.1093/icesjms/fsu102.

Hutchings, J.A. 1996. Spatial and temporal variation in the density of northern cod and a review of hypotheses for the stock's collapse. Can. J. Fish. Aquat. Sci. 53(5): 943962. doi:10.1139/f96-097.

Korman, J., Martell, S.J.D., Walters, C.J., Makinster, A.S., Coggins, L.G., Yard, M.D., Persons, W.R., and Quinn, T. 2012. Estimating recruitment dynamics and movement of rainbow trout ( Oncorhynchus mykiss ) in the Colorado River in Grand Canyon using an integrated assessment model. Can. J. Fish. Aquat. Sci. 69(11): 1827-1849. doi:10.1139/f2012-097.

Li, Y., Bence, J.R., and Brenden, T.O. 2015. An evaluation of alternative assessment approaches for intermixing fish populations: a case study with Great Lakes lake whitefish. ICES J. Mar. Sci. 72(1): 70-81. doi:10.1093/icesjms/fsu057. 
745

746

747

748

749

750

751

752

753

754

755

756

757

758

759

760

761

762

763

764

765

766

767

768

769

770

771

772

773

774

775

776

777

778

779

780

781

782

783

784

Li, Y., Bence, J.R., and Brenden, T.O. 2016. The influence of stock assessment frequency on the achievement of fishery management objectives. North Am. J. Fish. Manag. 36(4): 793-812. doi:10.1080/02755947.2016.1167145.

Li, Y., Bence, J.R., Zhang, Z., and Ebener, M.P. 2017. Why do lake whitefish move long distances in Lake Huron? Bayesian variable selection of factors explaining fish movement distance. Fish. Res. 195: 169-179. doi:10.1016/j.fishres.2017.07.014.

Maunder, M.N., and Deriso, R.B. 2003. Estimation of recruitment in catch-at-age models. Can. J. Fish. Aquat. Sci. 60(10): 1204-1216. doi:10.1139/f03-104.

Methot, R.D., and Taylor, I.G. 2011. Adjusting for bias due to variability of estimated recruitments in fishery assessment models. Can. J. Fish. Aquat. Sci. 68(10): 17441760. doi:10.1139/f2011-092.

Modeling Subcommittee, T.F.C. 2017. Technical fisheries committee administrative report 2017: status of lake trout and lake whitefish populations in the 1836 treatyceded waters of Lakes Superior, Huron and Michigan, with recommended yield and effort levels for 2017. doi:10.13140/RG.2.2.19581.15844.

Molton, K.J., Brenden, T.O., and Bence, J.R. 2012. Control rule performance for intermixing lake whitefish populations in the 1836 Treaty waters of the Great Lakes: A simulation-based evaluation. J. Great Lakes Res. 38(4): 686-698. doi:10.1016/j.jglr.2012.09.014.

Morishima, G.S., and Henry, K.A. 1999. The history and status of pacific northwest chinook and coho salmon ocean fisheries and prospects for sustainability. In Sustainable Fisheries Management: Pacific Salmon. Edited by E.E. Knudsen, C.R. Steward, D.D. MacDonald, J.E. Williams, and D.W. Reiser. CRC Press, Boca Raton, FL. pp. 219-236.

Paulik, G.J., Hourston, A.S., and Larkin, P.A. 1967. Exploitation of Multiple Stocks by a Common Fishery. J. Fish. Res. Board Canada 24(12): 2527-2537. doi:10.1139/f67202.

Porch, C.E., Turner, S.C., and Powers, J.E. 2001. Virtual population analyses of atlantic bluefin tuna with alternative models of transatlantic migration: 1970-1997. Int. Comm. Conserv. Atl. Tunas Collect. Vol. Sci. Pap. 52(3): 1022-1045.

R Core Team. 2016. R: A language and environment for statistical computing. R Found. Stat. Comput. doi:10.1007/978-3-540-74686-7.

Ricker, W.E. 1958. Maximum Sustained Yields from Fluctuating Environments and Mixed Stocks. J. Fish. Res. Board Canada 15(5): 991-1006. doi:10.1139/f58-054.

Stott, W., VanDeHey, J.A., and Sloss, B.L. 2010. Genetic diversity of lake whitefish in lakes Michigan and Huron; sampling, standardization, and research priorities. J. Great Lakes Res. 36(SUPPL. 1): 59-65. doi:10.1016/j.jglr.2010.01.004.

Vandergoot, C.S., and Brenden, T.O. 2014. Spatially varying population demographics and fishery characteristics of Lake Erie walleyes inferred from a long-term tag recovery study. Trans. Am. Fish. Soc. 143(1): 188-204.

https://mc06.manuscriptcentral.com/cjfas-pubs 
doi:10.1080/00028487.2013.837095.

786 Vincent, M.T., Brenden, T.O., and Bence, J.R. 2017. Simulation testing the robustness of

787

788

789 a multiregion, tag-integrated assessment model that exhibits natal homing and

790 Ying, Y., Chen, Y., Lin, L., and Gao, T. 2011. Risks of ignoring fish population spatial

791

792 structure in fisheries management. Can. J. Fish. Aquat. Sci. 68(12): 2101-2120.

793 
Table 1. Composition of the assessment input data and objective function for the four assessment models we evaluated.

\begin{tabular}{|c|c|c|c|c|c|}
\hline $\begin{array}{l}\text { Assessment } \\
\text { model }\end{array}$ & & $\begin{array}{l}\text { Standard } \\
\text { assessment } \\
\text { model } \\
\text { without a } \\
\text { recruitment } \\
\text { penalty (S) }\end{array}$ & $\begin{array}{l}\text { Standard } \\
\text { assessment } \\
\text { model with a } \\
\text { recruitment } \\
\text { penalty (S } \\
\text { W/Rec) }\end{array}$ & $\begin{array}{l}\text { Origin- } \\
\text { informed } \\
\text { assessment } \\
\text { without a } \\
\text { recruitment } \\
\text { penalty }(\mathrm{O})\end{array}$ & $\begin{array}{l}\text { Origin- } \\
\text { informed } \\
\text { assessment } \\
\text { with a } \\
\text { recruitment } \\
\text { penalty (O } \\
\text { W/Rec) } \\
\end{array}$ \\
\hline \multirow[t]{4}{*}{ Input data } & $\begin{array}{l}\text { Observed } \\
\text { harvest }\end{array}$ & $\checkmark$ & $\checkmark$ & $\checkmark$ & $\checkmark$ \\
\hline & $\begin{array}{l}\text { Observed } \\
\text { effort }\end{array}$ & $\checkmark$ & $\checkmark$ & $\checkmark$ & $\checkmark$ \\
\hline & $\begin{array}{l}\text { Aggregated } \\
\text { harvest age } \\
\text { composition }\end{array}$ & $\checkmark$ & $\checkmark$ & & \\
\hline & $\begin{array}{l}\text { Population- } \\
\text { specific } \\
\text { harvest age } \\
\text { composition }\end{array}$ & & 8 & $\checkmark$ & $\checkmark$ \\
\hline \multirow{3}{*}{$\begin{array}{l}\text { Objective } \\
\text { function } \\
\text { components } \\
\text { (negative log } \\
\text { likelihood or } \\
\text { log-prior } \\
\text { penalty for) }\end{array}$} & $\begin{array}{l}\text { Area-specific } \\
\text { fishery } \\
\text { harvest }\end{array}$ & $\checkmark$ & $\checkmark$ & $\checkmark$ & $\checkmark$ \\
\hline & $\begin{array}{l}\text { Annual } \\
\text { deviation } \\
\text { from the } \\
\text { general level } \\
\text { of fishing } \\
\text { mortality } \\
\end{array}$ & $\checkmark$ & $\checkmark$ & $\checkmark$ & $\checkmark$ \\
\hline & $\begin{array}{l}\text { Aggregate } \\
\text { harvest age } \\
\text { composition }\end{array}$ & $\checkmark$ & $\checkmark$ & & \\
\hline
\end{tabular}




\begin{tabular}{llcc}
\hline Population- & $\checkmark$ & $\checkmark$ \\
specific & & \\
harvest age & & $\checkmark$ \\
composition & Annual & & \\
recruitment & & \\
residuals & & \\
\hline
\end{tabular}


Table 2. Index variables and accents used in all equations.

\begin{tabular}{cl}
\hline Symbol & Definition \\
\hline$j$ & Population \\
$j$ & Fishing ground \\
$y$ & Year \\
$a$ & Age \\
$\sim$ & Observed variable \\
$\sim$ & Estimated variable \\
, & Derived variable \\
\hline
\end{tabular}


Table 3. Coefficients for parameters used to generate different levels of productivity, data quality, recruitment variation, and annual-varying random generated rates in both operating and stock assessment models.

\begin{tabular}{lll}
\hline $\begin{array}{l}\text { Coefficient } \\
\text { name }\end{array}$ & Definition Coefficient values
\end{tabular}

\begin{tabular}{|c|c|c|c|c|}
\hline \multicolumn{2}{|c|}{ Productivity levels } & Low & Baseline & High \\
\hline Steepness & S-R steepness & 0.7 & 1.3668 & 1.9 \\
\hline$\alpha^{\prime}$ & Ricker S-R parameter & 0.0003169815 & 0.0007316319 & 0.001104342 \\
\hline$\beta$ & Ricker S-R parameter & $1.511359 e^{-10}$ & $2.318631 e^{-10}$ & $2.716004 e^{-10}$ \\
\hline \multicolumn{2}{|c|}{ Data quality levels } & Low & Baseline & High \\
\hline eff $N$ & Effective sample size & 25 & 50 & 100 \\
\hline Harvest CV & $\begin{array}{l}\mathrm{CV} \text { for observed harvest } \\
\text { about actual harvest }\end{array}$ & 0.4 & 0.15 & 0.1 \\
\hline Effort CV & $\begin{array}{l}\mathrm{CV} \text { for observed harvest } \\
\text { about actual effort }\end{array}$ & 0.8 & 0.3 & 0.2 \\
\hline \multicolumn{2}{|c|}{ Annual-varying random generated rates } & Stay rate $=91 \%$ & Stay rate $=70 \%$ & Stay rate $=52 \%$ \\
\hline$\mu_{\omega}$ & Mean of $\omega_{y}$ & 2.313635 & 0.8472979 & 0.08004271 \\
\hline$\sigma_{\omega}^{2}$ & Variance of $\omega_{y}$ & 0.3364 & 0.0625 & 0.21 \\
\hline \multicolumn{2}{|c|}{$\underline{\text { Recruitment variation levels }}$} & $\begin{array}{c}\text { No } \\
\text { autocorrelation }\end{array}$ & Baseline & High \\
\hline$\rho$ & $\begin{array}{l}\text { Autocorrelation } \\
\text { coefficient }\end{array}$ & 0 & 0.45 & 0.45 \\
\hline$\sigma_{R}$ & $\begin{array}{l}\text { Innovative standard dev. } \\
\text { in rec process error }\end{array}$ & 0.8734 & 0.78 & 1.3395 \\
\hline$\sigma$ & $\begin{array}{l}\text { Stationary standard dev. } \\
\text { in rec process error }\end{array}$ & 0.8734 & 0.8734 & 1.5 \\
\hline \multicolumn{2}{|c|}{$\underline{\text { Target mortality levels }}$} & Low & Baseline (Status & \\
\hline
\end{tabular}


A

$\begin{array}{lll}\text { Annual total mortality } & 0.55 & 0.65\end{array}$

rate 
Table 4. Biomass calculation in the operating model.

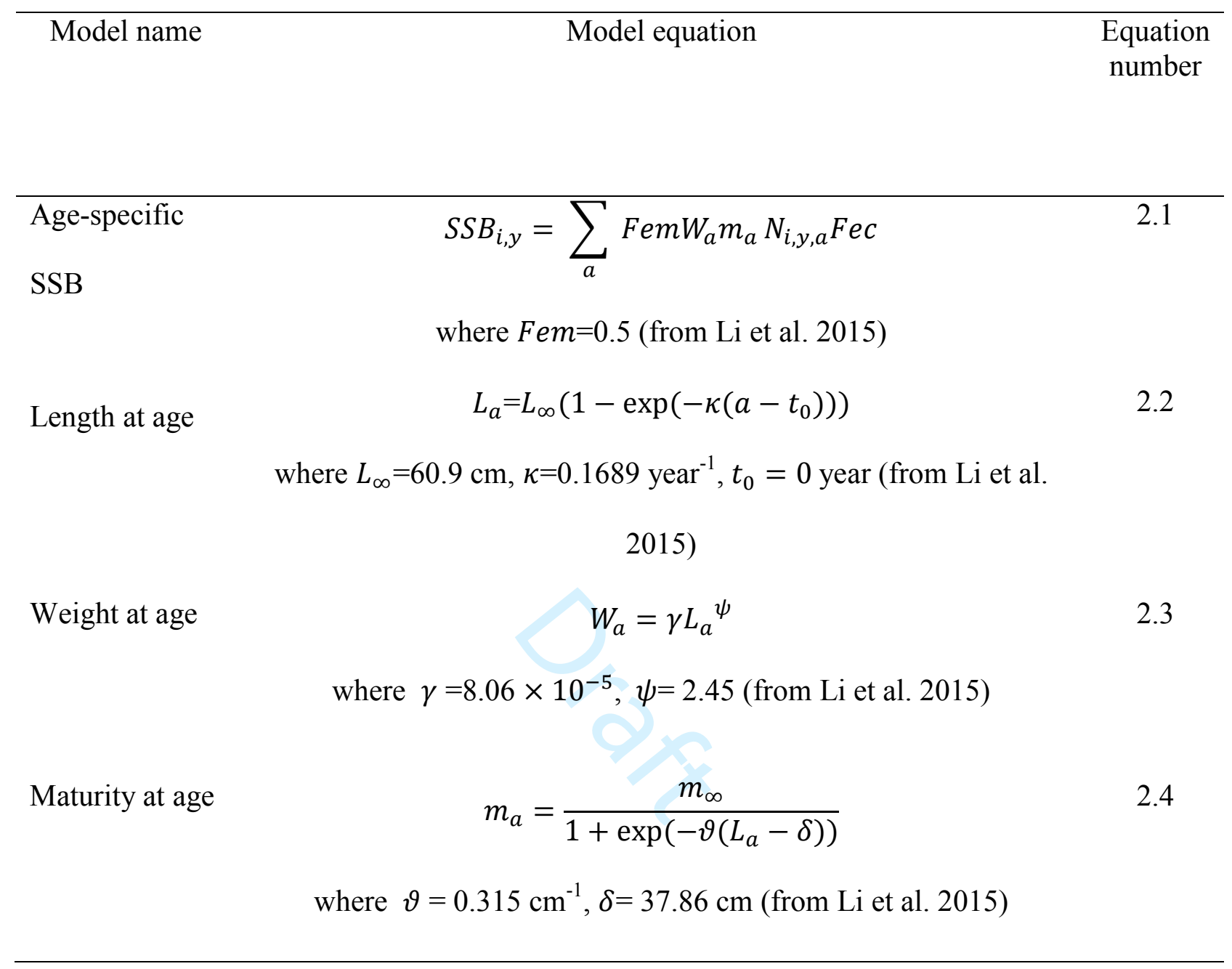


Table 5. Simulation scenarios, including the baseline scenario and other combinations of productivity levels and stay rates, for four hypothetic populations used in the simulations.

\begin{tabular}{|c|c|c|c|c|}
\hline $\begin{array}{l}\text { Scenario } \\
\text { index }\end{array}$ & Scenario & $\begin{array}{l}\text { Population } \\
\text { identifier }\end{array}$ & Productivity & $\begin{array}{l}\text { Stay } \\
\text { rate }\end{array}$ \\
\hline \multirow{4}{*}{$\begin{array}{l}\text { Baseline } \\
\text { (1) }\end{array}$} & \multirow[t]{4}{*}{ Equal mixing with baseline productivity } & Pop1 & Baseline & $70 \%$ \\
\hline & & Pop2 & Baseline & $70 \%$ \\
\hline & & Pop3 & Baseline & $70 \%$ \\
\hline & & Pop4 & Baseline & $70 \%$ \\
\hline \multirow{4}{*}{2} & \multirow[t]{4}{*}{ Equal mixing with different productivity } & Pop1 & Low & $70 \%$ \\
\hline & & Pop2 & Low & $70 \%$ \\
\hline & & Pop3 & High & $70 \%$ \\
\hline & & Pop4 & High & $70 \%$ \\
\hline \multirow{4}{*}{3} & \multirow{4}{*}{ Unequal mixing with baseline productivity } & Pop1 & Baseline & $91 \%$ \\
\hline & & Pop2 & Baseline & $91 \%$ \\
\hline & & Pop3 & Baseline & $52 \%$ \\
\hline & & Pop4 & Baseline & $52 \%$ \\
\hline \multirow{4}{*}{4} & \multirow{4}{*}{$\begin{array}{l}\text { Unequal mixing with different productivity } \\
\text { (Positive correlation between productivity } \\
\text { and stay rates) }\end{array}$} & Pop1 & Low & $52 \%$ \\
\hline & & Pop2 & Low & $52 \%$ \\
\hline & & Pop3 & High & $91 \%$ \\
\hline & & Pop4 & High & $91 \%$ \\
\hline \multirow{4}{*}{5} & \multirow{4}{*}{$\begin{array}{l}\text { Unequal mixing with different productivity } \\
\text { (Negative correlation between productivity } \\
\text { and stay rates) }\end{array}$} & Pop1 & Low & $91 \%$ \\
\hline & & Pop2 & Low & $91 \%$ \\
\hline & & Pop3 & High & $52 \%$ \\
\hline & & Pop4 & High & $52 \%$ \\
\hline
\end{tabular}


Table 6. Scenarios for sensitivity analyses. In each sensitivity scenario, except for the change descripted below all other parameters are at their baseline levels.

\begin{tabular}{|c|c|c|}
\hline Scenario index & Description & $\begin{array}{l}\text { Description of change from } \\
\text { baseline scenario }\end{array}$ \\
\hline Dat_L & $\begin{array}{l}\text { Data quality levels (Table } 3 \text { ) } \\
\text { all low. }\end{array}$ & Data quality \\
\hline Dat_H & $\begin{array}{l}\text { Data quality levels (Table } 3 \text { ) } \\
\text { all high. }\end{array}$ & Data quality \\
\hline MixV_Ass & $\begin{array}{l}\text { Allowed mixing rates in the } \\
\text { assessment model to vary } \\
\text { annually about the true value } \\
\text { assumed in the operating } \\
\text { model. }\end{array}$ & $\begin{array}{l}\text { Mixing rates in the assessment } \\
\text { model }\end{array}$ \\
\hline RecV_H & $\begin{array}{l}\text { Recruitment variation levels } \\
\text { (Table } 3 \text { ) all high. }\end{array}$ & Recruitment variation \\
\hline RecV_0 & $\begin{array}{l}\text { Recruitment variation levels } \\
\text { (Table } 3 \text { ) all no } \\
\text { autocorrelation. }\end{array}$ & Recruitment variation \\
\hline $\operatorname{Tar} A=55 \%$ & $\begin{array}{l}\text { Target mortality levels all low } \\
\text { (Table } 3 \text { ). }\end{array}$ & Target mortality \\
\hline
\end{tabular}




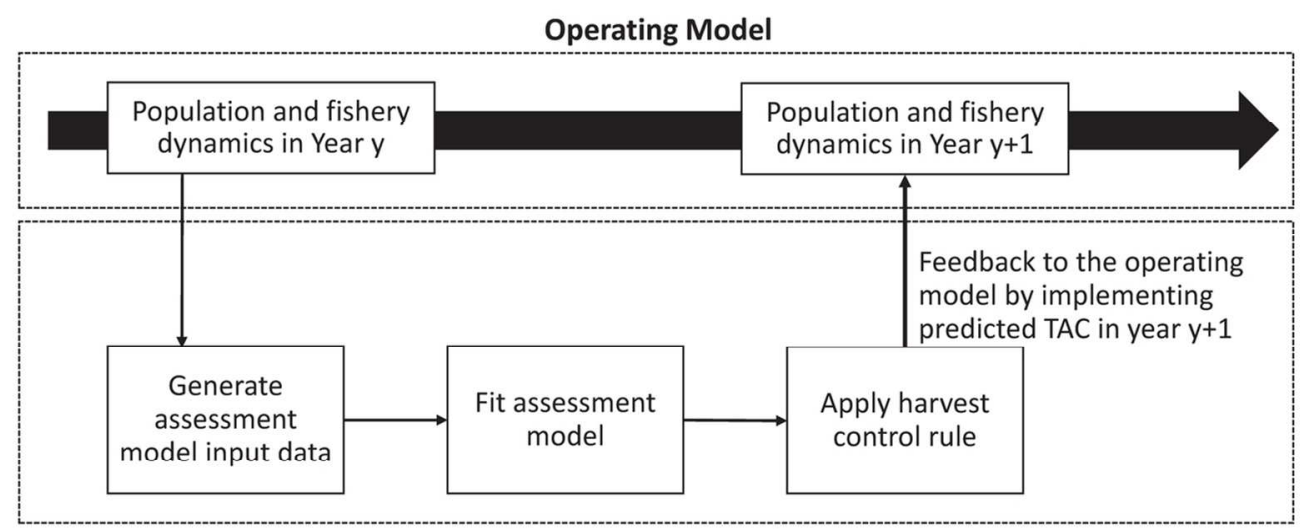

Management Procedure

Figure 1. The full closed-loop feedback simulation framework, which followed a management strategy evaluation approach.

$110 \times 47 \mathrm{~mm}(300 \times 300 \mathrm{DPI})$ 


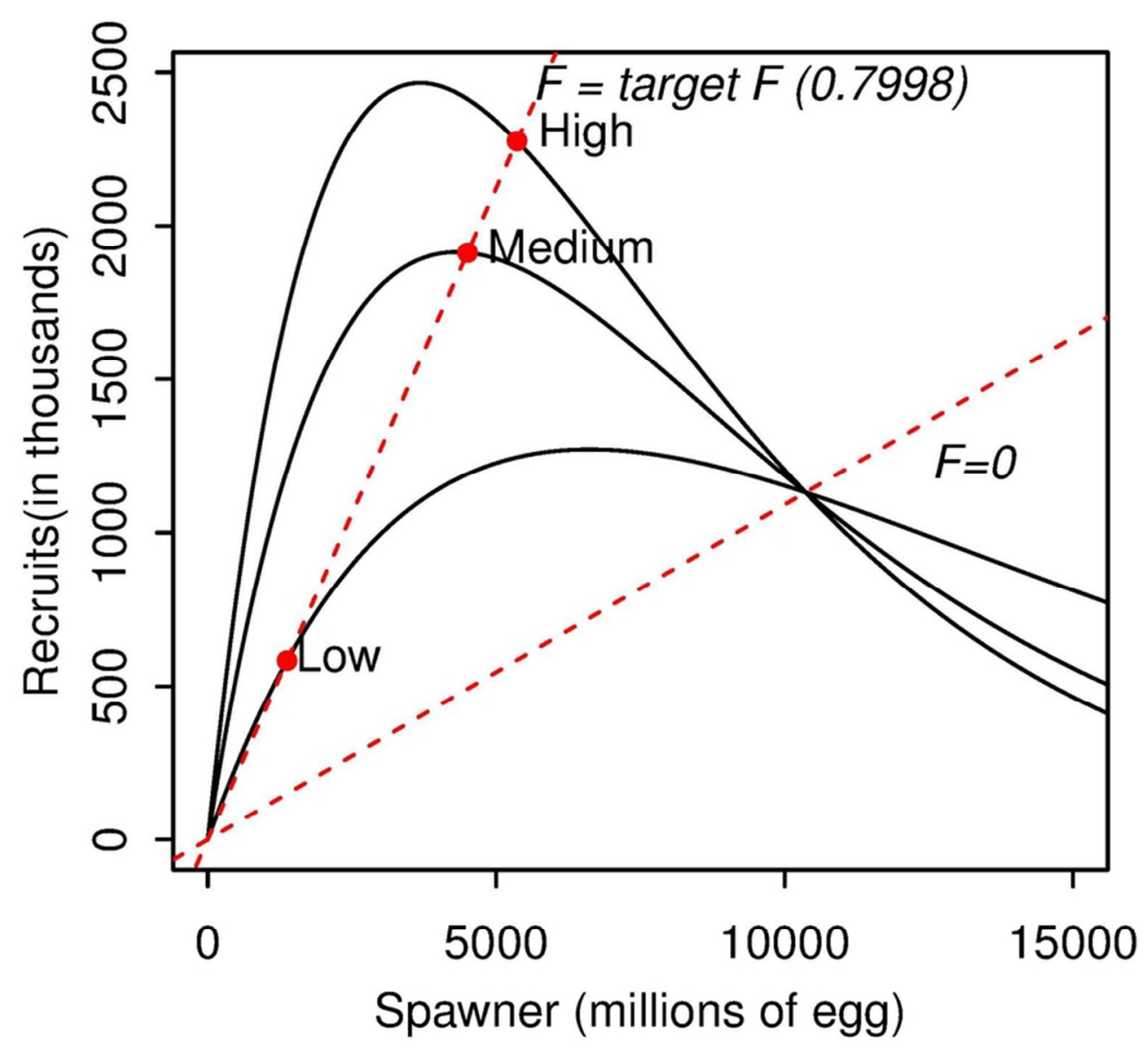

Figure 2. Ricker stock-recruitment relationships for populations with low, medium, and high level of productivity (Table 3 ). Two dashed lines represent the replacement lines for $F=0$ and target $F$ and their intersections with stock-recruitment curves (dots) define equilibrium for low, baseline, and high productivity. Note that the target $F$ is calculated based on the natural mortality rate and the status quo target total mortality ( $A=0.65$ ).

$76 \times 68 \mathrm{~mm}(300 \times 300 \mathrm{DPI})$ 
a)

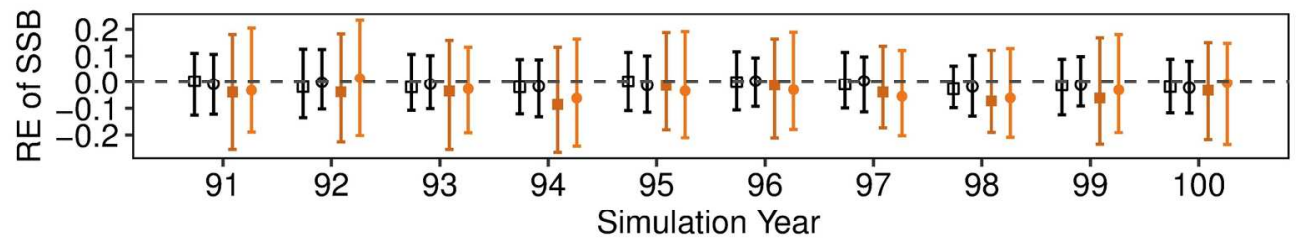

b)

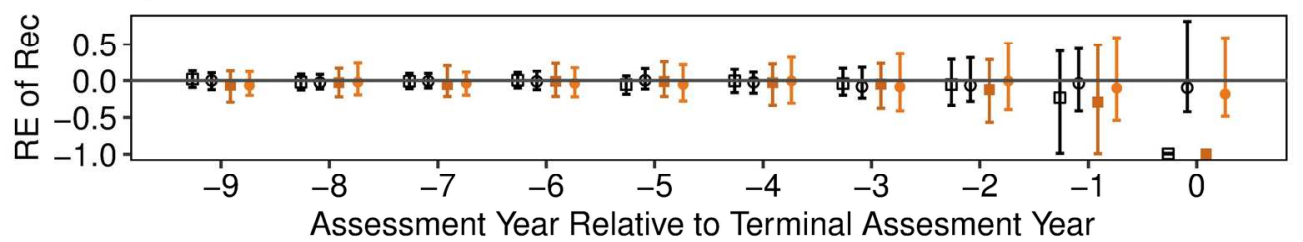

c)

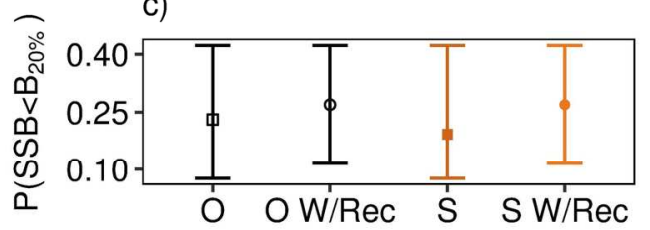

e)

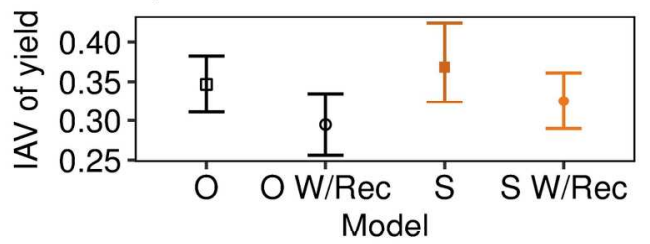

d)
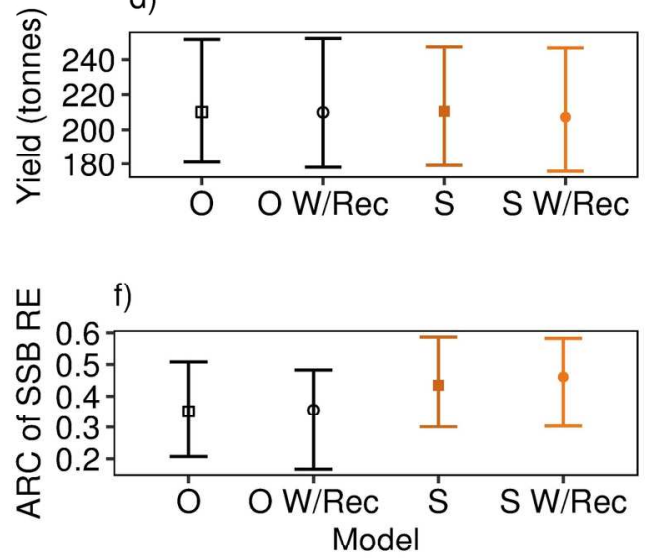

Model $\longrightarrow \mathrm{O} \longrightarrow \mathrm{OW} / \mathrm{Rec} \longrightarrow \mathrm{S} \longrightarrow \mathrm{S}$ W/Rec

Figure 3. Simulation results (median \pm interquartile range) for population 1 (Table 5 ) in the baseline scenario. Full model names are in Table 1. (a) Relative error of estimating terminal assessment year SSB during simulation year 91 to100. (b) In simulation year 100, relative error of estimating recruitment of the last ten assessment years. (c) Proportion of years SSB was lower than $20 \%$ of the unfished SSB level

(B20\%) over the last 25 years of simulations. (d) Mean annual yield for the fishing area surrounding spawning grounds of Pop1 over the last 25 years of simulations. (e) Mean interannual variation (IAV) in yield over the last 25 years of simulation. (f) Estimated autocorrelation for terminal year estimates of SSB during simulation years 75 to 100 .

$170 \times 170 \mathrm{~mm}(300 \times 300 \mathrm{DPI})$ 


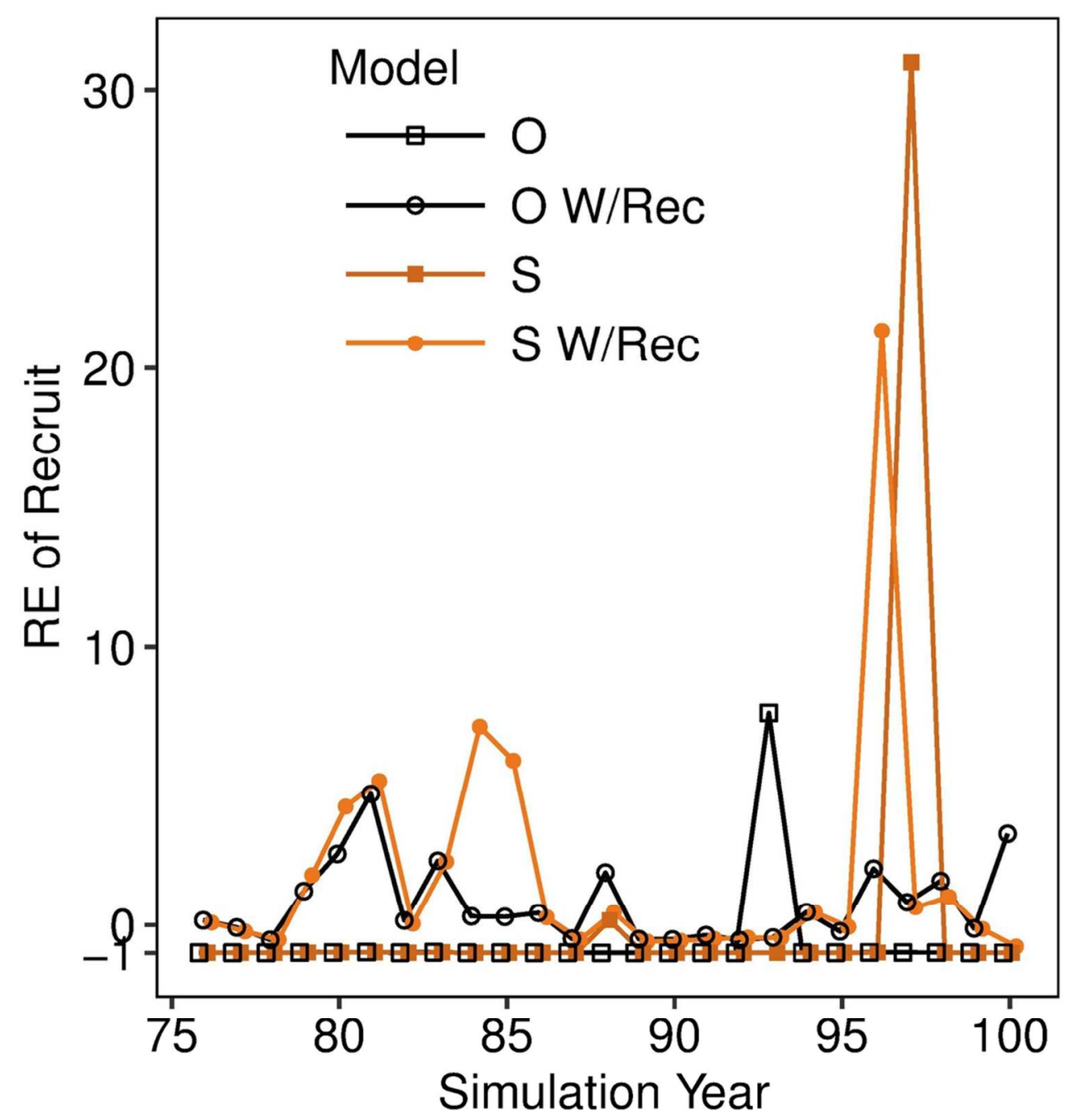

Figure 4. Relative error in estimates of recruitment for the terminal assessment year during the simulation year 76 to 100 for an example simulation. Full model names are in Table 1.

$99 \times 104 \mathrm{~mm}(300 \times 300 \mathrm{DPI})$ 

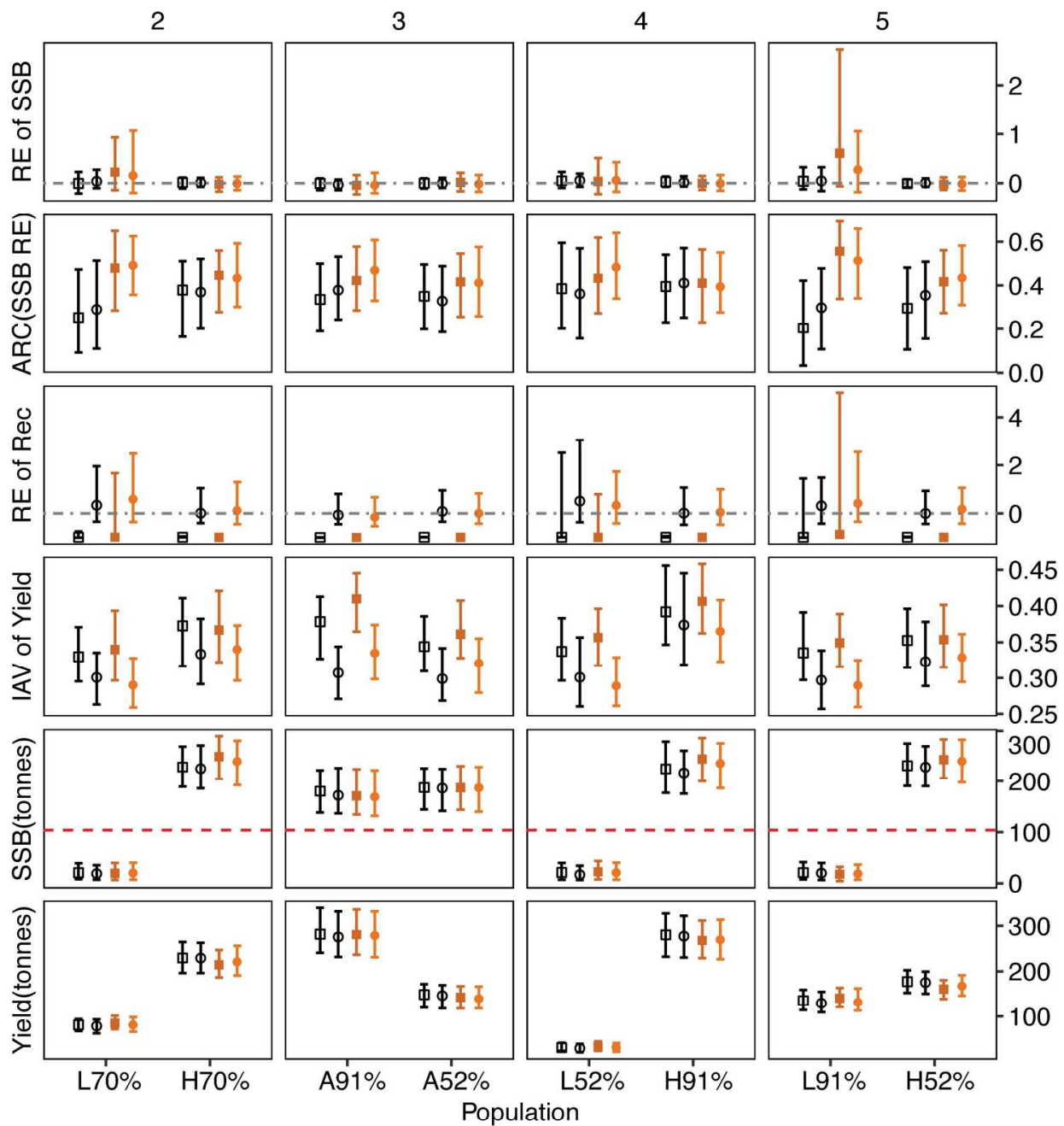

Model
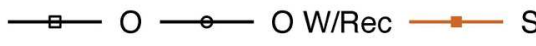

$\mathrm{S} \longrightarrow \mathrm{S}$ W/Rec

Figure 5. Simulation results (median \pm interquartile range) for populations 1 and 3 under scenarios 2 to 5 (Table 5). Full model names are in Table 1. Each column represents a different productivity and movement scenario, and each row presents a different performance statistic. The x-axis of each column indicates the productivity levels ( $\mathrm{L}, \mathrm{A}, \mathrm{H}$ are low, average, and high productivity levels) and stay rates associated with the two populations results are presented for. For example, L70\% means low productivity population with $70 \%$ stay rate. For each such productivity level and stay rate, results are given for the four different assessment methods, distinguished by different symbols. The second, fourth, and sixth rows represents the same performance statistics as for Figure 3c, 3e, and 3d. The first and third row are relative error of estimating terminal year SSB and recruitment in simulation year 100, respectively, with a 0 dashed line. The fifth row represents the average SSB over the last 25 years of simulation, and the dashed line is $20 \%$ of the unfished SSB.

$189 \times 212 \mathrm{~mm}(300 \times 300 \mathrm{DPI})$ 


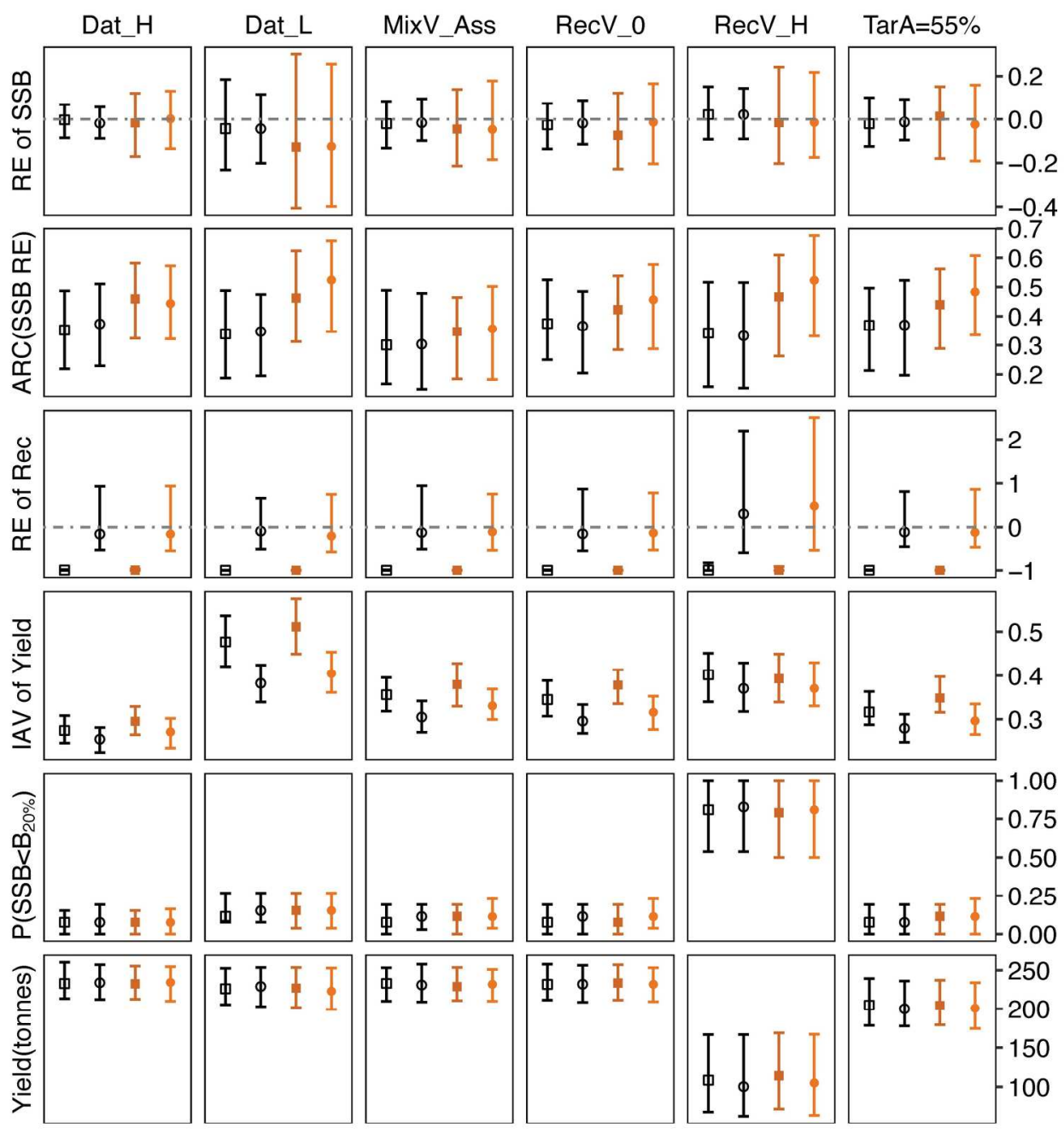

Model $\longrightarrow \mathrm{O} \longrightarrow \mathrm{OW} / \mathrm{Rec} \longrightarrow \mathrm{S} \longrightarrow \mathrm{SW} / \mathrm{Rec}$

Figure 6. Simulation results (median \pm interquartile range) for Pop1 (Table 5) in sensitivity analyses. Full model names are in Table 1. Each column represents a sensitivity scenario, each row represents a performance metric (as described in Figure 5), and results in each panel are for the four assessment models.

$189 \times 212 \mathrm{~mm}(300 \times 300$ DPI $)$ 